\title{
Determinan Kejadian Unmet Need KB Di Wilayah Kerja Puskesmas Peukan Bada Kabupaten Aceh Besar Tahun 2019
}

\section{Determinants of Unmet Need at Working Area of Puskesmas Peukan Bada Aceh Besar in 2019}

\author{
Faradilla Safitri ${ }^{1}$, Icha Kana ${ }^{2}$ \\ ${ }^{1}$ Universitas Ubudiyah Indonesia, Jln. Alue Naga Desa Tibang, Kecamatan Syiah Kuala, Banda Aceh, Indonesia \\ ${ }^{2}$ Universitas Ubudiyah Indonesia, Jln. Alue Naga Desa Tibang, Kecamatan Syiah Kuala, Banda Aceh, Indonesia \\ *Correspoding Author : faradilla@uui.ac.id ${ }^{1}$, icha.kana1797@gmail.com²
}

\begin{abstract}
Abstrak
Unmet need $\mathrm{KB}$ merupakan permasalahan yang bersifat multidimensional dan bukan hanya akan menjadi penyebab ledakan populasi melainkan juga bisa berpengaruh pada tingginya Angka Kematian Ibu (AKI) di Iindonesia. Persentase unmet need secara nasional sendiri pada tahun 2015 sebesar 14,87\%. Unmet need KB di provinsi Aceh berjumlah 14,25\% dan dengan presentase angka kejadian di Aceh Besar sebanyak (16,28\%). Tujuan penelitian ini adalah untuk mengetahui determinan kejadian unmet need $\mathrm{KB}$ di Wilayah Kerja Puskesmas Peukan Bada Kabupaten Aceh Besar Tahun 2019. Jenis penelitian bersifat analitik dengan pendekatan cross sectional. Penelitian telah dilaksanakan pada bulan 10-30 Juni tahun 2019 di Wilayah Kerja Puskesmas Peukan Bada Kabupaten Aceh Besar. Pengambilan sampel secara purposive sampling dengan jumlah sampel 32 orang. Instrumen penelitian menggunakan kuesioner dan teknik pengumpulan data dengan cara wawancara. Analisa data dengan cara univariat, bivariate dan multivariate. Hasil penelitian analisis bivariat didapat determinan umur $(\mathrm{p}=0,000, \mathrm{OR}=27,00)$, pendidikan $(\mathrm{p}=0,002, \mathrm{OR}=17,00)$, pengetahuan $(p=0,018$, OR=7,93), jumlah anak $(p=0,002)$, dukungan suami $(p=0,006$, $\mathrm{OR}=12,60)$ dan peran petugas kesehatan $(\mathrm{p}=0,002, \mathrm{OR}=18,00)$. Hasil analisis multivariate didapat faktor yang paling dominan adalah peran petugas kesehatan $(\mathrm{OR}=11,379)$. Dapat disimpulkan bahwa ada hubungan umur, pendidikan, pengetahuan, jumlah anak, dukungan suami, dan peran petugas kesehatan dengan kejadian Unmet need $\mathrm{KB}$ di Wilayah Kerja Puskesmas Peukan Bada Kabupaten Aceh Besar. Diharapkan kepada para petugas kesehatan agar dapat lebih memberikan edukasi kepada masyarakat berupa penyuluhan kesehatan keluarga berencana, sehingga dapat menurunkan angka kejadian unmet need.
\end{abstract}

Kata Kunci : Unmet Need KB, peran petugas kesehatan

\section{Abstract}

Unmet need in family planning is a multidimensional problem and will not only be a cause of population explosion but can also affect the high maternal mortality rate (MMR) in Indonesia. The percentage of national unmet need itself in 2015 was 14.87\%. Unmet need needs in the province of Aceh amounted to $14.25 \%$ and with a percentage of the incidence in Aceh Besar as much (16.28\%). The purpose of this study was to determinants of unmet need at working area of Puskesmas Peukan Bada Aceh Besar in 2019. This type of research is analytic with cross sectional approach. The research was carried out on 10-30 June 2019 in at working area of Puskesmas Peukan Bada Aceh Besar. Sampling by purposive sampling with a sample of 32 people. The research instrument used a questionnaire and data collection 
Journal of Healthcare Technology and Medicine Vol. 5 No. 2 Oktober 2019

Universitas Ubudiyah Indonesia

e-ISSN : 2615-109X

techniques by interview. Analysis of data by univariate, bivariate and multivariate methods. The results of the bivariate analysis obtained determinants of age $(p=0,000, O R=27.00)$, education $(p=0.002$, OR $=17.00)$, knowledge $(p=0.018$, OR $=7.93)$, number of children $(p=0.002)$, husband support $(p=0.006, O R=12.60)$ and health workers role $(p=0.002$, $O R=18.00)$. The results of multivariate analysis found that the most dominant factor was health workers role $(O R=11,379)$. It can be concluded that there is a relationship between age, education, knowledge, number of children, husband's support, and the role of health workers with the Unmet need events at working area of Puskesmas Peukan Bada Aceh Besar. It is expected that health workers can provide more education to the community in the form of family planning health education, so as to reduce the number of unmet need events.

Keyword: Unmet Need, health workers role

\section{PENDAHULUAN}

Keluarga Berencana (KB) merupakan upaya untuk meningkatkan derajat kesehatan dan kesejahteraan ibu dan anak, keluarga serta masyarakat pada umumnya. Keberhasilan pelaksanaan keluarga berencana diharapkan angka kelahiran dapat diturunkan, sehingga tingkat kecepatan perkembangan penduduk tidak melebihi kemampuan kenaikan produksi, dengan demikian taraf kehidupan dan kesejahteraan rakyat diharapkan akan lebih meningkat ${ }^{1}$.

Berdasarkan Undang-Undang Nomor 52 Tahun 2009 tentang Perkembangan Kependudukan dan Pembangunan Keluarga menyatakan bahwa pembangunan keluarga adalah upaya mewujudkan keluarga berkualitas yang hidup dalam lingkungan yang sehat; dan Keluarga Berencana (KB) adalah upaya mengatur kelahiran anak, jarak dan usia ideal melahirkan, mengatur kehamilan melalui promosi, perlindungan dan banyian sesuai hak reproduksi untuk mewujudkan keluarga berkualitas ${ }^{2}$.

Menurunnya rata-rata laju pertumbuhan penduduk dan meningkatnya angka kesertaan ber-KB setiap tahunnya menjadi sasaran pokok pembangunan kependudukan dan keluarga berencana didalam RPJMN 2015-2019. Meskipun jumlah peserta KB aktif meningkat, jumlah tersebut masih belum mampu mempertahankan dam meningkatkan angka prevalensi pemakaian kontrasepsi ${ }^{3}$.

Data Susenas menunjukkan kecenderungan penurunan pemakaian kontrasepsi dari 61,75\% pada tahun 2014 menjadi 59,98\% tahun 2015 untuk suatu cara dan dari 60,64\% (2014) menjadi 58,99\% (2015) untuk cara modern. Sulitnya peningkatan angka kesertaan ber-KB antara lain disebabkan oleh masih tingginya kekhawatiran pasangan usia subur (PUS) terhadap efek samping pemakanan alat kontrasepsi sebesar $18,30 \%{ }^{3}$. 
Journal of Healthcare Technology and Medicine Vol. 5 No. 2 Oktober 2019

Universitas Ubudiyah Indonesia

e-ISSN : 2615-109X

Hasil Survei Demografi dan Kesehatan pada tahun 2017 terlihat bagaimana potret Program Kependudukan, Keluarga Berencana dan Pembangunan Keluarga (KKBPK) salah satunya yaitu Provinsi Aceh menempati urutan ke 31 dari 35 provinsi dengan pemakaian kontrasepsi tahun 2017 sebesar 51,6\%, artinya Aceh menjadi salah satu provinsi yang lebih dari 50,0\% pasangan usia subur tidak menggunakan alat konrasepsi ${ }^{4}$.

Unmet Need merupakan pasangan usia subur yang tidak ingin punya anak lagi atau yang ingin menjarangkan kelahiran, tetapi tidak menggunakan kontrasepsi ${ }^{2}$. Unmet Need Keluarga Berencana atau kebutuhan KB yang belum terpenuhi adalah pada proporsi wanita yang tidak sedang hamil dan tidak sedang amenora postpartum, dan dalam keadaan subur, dan ingin menunda kehamilan dalam waktu 2 tahun yang akan datang atau tidak ingin anak lagi, tetapi tidak menggunakan alat/cara KB, persentase unmet need di Indonesia tertinggi di Provinsi Papua Barat yaitu sebesar 38,23\%. Sedangkan persentase unmet need yang terendah yaitu di provinsi Bali sebesar $5,12 \%{ }^{5}$.

Provinsi Aceh merupakan salah satu provinsi di Indonesia yang mempunyai unmet need yang cukup tinggi. Berdasarkan Rapat Pengendalian Program (Radalgram) BKKBN Aceh (2016), unmet need KB di Aceh berjumlah 14,25\% dari 791.816 PUS dengan rincian dari 23 Kabupaten/ Kota, terdapat jumlah unmet need-nya tinggi terdapat di 16 Kabupaten/ Kota yaitu Aceh Singkil (31,82\%), Simeulue (30,86\%), Aceh Jaya (28,14\%), Kota Subussalam (22,32\%), Aceh Utara (19,24\%), Aceh Tenggara (18,66\%), Aceh Barat $(17,95 \%)$, Pidie (16,83\%), Aceh Selatan (16,69\%), Aceh Besar (16,28\%), Kota Banda Aceh $(15,68 \%)$, Pidie Jaya (14,84\%), Kota Sabang (14,14\%), Nagan Raya (13,78\%), Aceh Timur $(13,75 \%)$ dan Kota Langsa $(13,55 \%)^{6}$.

\section{METODE PENELITIAN}

Penelitian ini menggunakan jenis penelitian yang bersifat survey analitik dengan desain cross-sectional. Populasi dalam penelitian ini adalah seluruh wanita usia subur yang telah menikah dan memili anak sebanyak 831 orang. Pengambilan sampel dalam penelitian dengan cara purposive sampling dengan jumlah sampel sebanyak 32 orang. Instrumen pengumpulan data menggunakan kuesioner dengan cara wawancara. Pengumpulan data telah dilaksanakan pada tanggal 10 s/d 30 Juni 2019 di Wilayah Kerja Puskesmas Peukan Bada. Pengolahan data menggunakan komputer melalui proses editing, coding, tranfering, tabulating. Analisis data dengan tiga data yaitu analisis univariate, bivariate dan multivariate. 
Journal of Healthcare Technology and Medicine Vol. 5 No. 2 Oktober 2019

Universitas Ubudiyah Indonesia

e-ISSN : 2615-109X

\section{HASIL DAN PEMBAHASAN}

Tabel 1

Hubungan determinan umur, pendidikan, pengetahuan, jumlah anak, dukungan suami dan peran petugas kesehatan dengan kejadian unmet need $\mathrm{KB}$ di wilayah kerja Puskesmas Peukan Bada Aceh Besar Tahun 2019

\begin{tabular}{|c|c|c|c|c|c|c|c|c|c|}
\hline \multirow[t]{3}{*}{ No } & \multirow[t]{3}{*}{ Variabel } & \multicolumn{4}{|c|}{ Kejadian Unmet Need KB } & \multirow{2}{*}{\multicolumn{2}{|c|}{ Jumlah }} & \multirow[t]{3}{*}{ P Value } & \multirow[t]{3}{*}{$\mathbf{O R}$} \\
\hline & & \multicolumn{2}{|c|}{ Ya } & \multicolumn{2}{|c|}{ Tidak } & & & & \\
\hline & & $\mathbf{f}$ & $\%$ & $\mathbf{f}$ & $\%$ & $\mathbf{n}$ & $\%$ & & \\
\hline \multirow[t]{3}{*}{1} & Umur & & & & & & & & \\
\hline & a. $>35$ tahun & 9 & 81,8 & 2 & 18,2 & 11 & 100,0 & 0,000 & 27,00 \\
\hline & b. $\leq 35$ tahun & 3 & 14,3 & 18 & 85,7 & 21 & 100,0 & & \\
\hline \multirow[t]{3}{*}{2} & Pendidikan & & & & & & & & \\
\hline & a. Rendah $(<\mathrm{SMA})$ & 9 & 75,0 & 3 & 25,0 & 12 & 100,0 & 0,002 & 17,00 \\
\hline & b. Tinggi ( $\geq$ SMA) & 3 & 15,0 & 17 & 85,0 & 20 & 100,0 & & \\
\hline \multirow[t]{3}{*}{3} & Pengetahuan & & & & & & & & \\
\hline & a. Rendah & 7 & 70,0 & 3 & 30,0 & 10 & 100,0 & 0,018 & 7,93 \\
\hline & b. Tinggi & 5 & 22,7 & 17 & 77,3 & 22 & 100,0 & & \\
\hline \multirow[t]{3}{*}{4} & Jumlah Anak & & & & & & & & \\
\hline & a. $\leq 2$ anak & 12 & 57,1 & 9 & 42,9 & 21 & 100,0 & 0,002 & - \\
\hline & b. $>2$ anak & 0 & 0,0 & 11 & 100,0 & 11 & 100,0 & & \\
\hline \multirow[t]{3}{*}{5} & Dukungan Suami & & & & & & & & \\
\hline & a. Kurang & 7 & 77,8 & 2 & 22,2 & 9 & 100,0 & 0,006 & 12,60 \\
\hline & b. Baik & 5 & 21,7 & 18 & 78,3 & 23 & 100,0 & & \\
\hline \multirow[t]{3}{*}{6} & Peran Petugas & & & & & & & & \\
\hline & $\begin{array}{l}\text { Kesehatan } \\
\text { a. Kurang }\end{array}$ & 8 & 80,0 & 2 & 20,0 & 10 & 100,0 & 0,002 & 18,00 \\
\hline & b. Baik & 4 & 18,2 & 18 & 81,8 & 22 & 100,0 & & \\
\hline
\end{tabular}

Berdasarkan Tabel 1. dapat dilihat bahwa, dari 11 responden berumur $>35$ tahun dan unmet need $\mathrm{KB}$ sebanyak $9(81,8 \%)$ orang, sedangkan dari 21 responden berumur $\leq 35$ tahun dan unmet need $\mathrm{KB}$ sebanyak $3(14,3 \%)$ orang. Hasil uji hasil statistik didapat nilai $\mathrm{p}=$ 0,000, yang artinya ada hubungan umur dengan kejadian unmet need $\mathrm{KB}$ di wilayah kerja Puskesmas Peukan Bada Kabupaten Aceh Besar Tahun 2019, dan nilai OR = 27,00, yang berarti wanita yang berumur lebih dari 35 tahun memiliki peluang 27 kali lebih besar terjadinya unmet need $\mathrm{KB}$ dibandingkan dengan wanita yang berumur dibawah 35 tahun. 
Journal of Healthcare Technology and Medicine Vol. 5 No. 2 Oktober 2019

Universitas Ubudiyah Indonesia

e-ISSN : 2615-109X

Pada variabel pendidikan dapat dilihat bahwa, dari 12 responden, berpendidikan rendah dan unmet need $\mathrm{KB}$ sebanyak $9(75,0 \%)$ orang, sedangkan dari 20 responden yang berpendidikan tinggi dan unmet need KB sebanyak $3(15,0 \%)$ orang. Hasil uji statistik didapat nilai $\mathrm{p}=0,002$, yang artinya ada hubungan pendidikan dengan kejadian unmet need KB di wilayah kerja Puskesmas Peukan Bada Kabupaten Aceh Besar Tahun 2019, dan nilai OR $=17,00$, yang berarti wanita berpendidikan rendah memiliki peluang 17 kali lebih besar terjadinya unmet need KB dibandingkan dengan wanita yang berpendidikan tinggi.

Pada variabel pengetahuan dapat dilihat bahwa, dari 10 responden, berpengetahuan rendah dan unmet need $\mathrm{KB}$ sebanyak 7 (70,0\%) orang, sedangkan dari 22 responden yang berpendidikan tinggi dan unmet need KB sebanyak 5 (22,7\%) orang. Hasil uji statistik didapat nilai $\mathrm{p}=0,018$, yang artinya ada hubungan pengetahuan dengan kejadian unmet need KB di wilayah kerja Puskesmas Peukan Bada Kabupaten Aceh Besar Tahun 2019, dan nilai $\mathrm{OR}=7,93$, yang berarti wanita berpengetahuan rendah memiliki peluang 7 kali lebih besar terjadinya unmet need $\mathrm{KB}$ dibandingkan dengan wanita yang berpengetahuan tinggi.

Pada variabel jumlah anak dapat dilihat bahwa, dari 21 responden, yang memiliki jumlah anak $\leq 2$ dan unmet need $\mathrm{KB}$ sebanyak 12 (57,1\%) orang. Hasil uji statistik didapat nilai $\mathrm{p}=0,002$, yang berarti ada hubungan jumlah anak dengan kejadian unmet need $\mathrm{KB}$ di wilayah kerja Puskesmas Peukan Bada Kabupaten Aceh Besar Tahun 2019.

Pada variabel dukungan suami dapat dilihat bahwa dari 9 responden, yang kurang mendapatkan dukungan dam unmet need KB sebanyak 7 (77,8\%) orang, sedangkan dari 23 responden, yang baik mendapatkan dukungan suami dan unmet need KB sebanyak 5 (21,7\%) orang. Hasil uji statistik didapat nilai $\mathrm{p}=0,006$, yang artinya ada hubungan dukungan suami dengan kejadian unmet need KB di wilayah kerja Puskesmas Peukan Bada Kabupaten Aceh Besar Tahun 2019, dan nilai OR $=12,60$, yang berarti wanita yang kurang mendapatkan dukungan suami memiliki peluang 12 kali lebih besar terjadinya unmet need $\mathrm{KB}$ dibandingkan dengan wanita yang mendapatkan dukungan suami.

Pada variabel peran petugas kesehatan dapat dilihat bahwa dari 10 responden, yang peran petugas kesehatannya kurang dan unmet need KB sebanyak 8 (80,0\%) orang, sedangkan dari 22 responden, yang peran petugas kesehatannya baik dan unmet need $\mathrm{KB}$ sebanyak $4(18,2 \%)$ orang. Hasil uji statistik didapatkan nilai $\mathrm{p}=0,002$, yang artinya ada hubungan peran petugas kesehatan dengan kejadian unmet need $\mathrm{KB}$ di wilayah kerja Puskesmas Peukan Bada Kabupaten Aceh Besar Tahun 2019, dan nilai OR = 18,00, yang 
Journal of Healthcare Technology and Medicine Vol. 5 No. 2 Oktober 2019

Universitas Ubudiyah Indonesia

e-ISSN : 2615-109X

berarti kurangnya peran petugas kesehatan dalam memberikan informasi tentang penggunaan alat kontrasepsi memiliki peluang 18 kali lebih besar terjadinya unmet need KB.

Tabel 2

Pemodelan Multivariat Pertama

\begin{tabular}{|c|c|c|c|}
\hline No & Variabel & p value & OR \\
\hline 1 & Umur & 0,999 & 1,004 \\
\hline 2 & Pendidikan & 0,999 & 9,179 \\
\hline 3 & Pengetahuan & 0,997 & 1,010 \\
\hline 4 & Jumlah Anak & 0,999 & 5,475 \\
\hline 5 & Dukungan Suami & 1,000 & 2,927 \\
\hline 6 & Peran Petugas Kesehatan & 0,711 & 0,500 \\
\hline
\end{tabular}

Hasil pemodelan pertama multivariat ternyata semua variabel independen dengan $p$ value $>0,05$, langkah selanjutnya setelah dilakukan sebanyak 5 kali pemodelan didapatkan hasil akhir sebagai berikut :

Tabel 3

Pemodelan Multivariat Terakhir

\begin{tabular}{clcc}
\hline No & Variabel & p value & OR \\
\hline 1 & Pendidikan & 0,019 & 11,100 \\
2 & Peran Petugas Kesehatan & 0,026 & 11,379 \\
\hline
\end{tabular}

Hasil pemodelan analisis multivariat terakhir terdapat 2 variabel yang berhubungan dengan kejadian pre eklampsia yaitu pendidikan dan peran petugas kesehatan. Dari kedua variabel tersebut, variabel yang dominan berhubungan dengan kejadian unmet need $\mathrm{KB}$ di Wilayah Kerja Puskesmas Peukan Bada Kabupaten Aceh Besar Tahun 2019 adalah peran petugas kesehatan dengan nilai $\mathrm{OR}=11,379$, artinya petugas kesehatan yang kurang berperan dalam pemberian informasi tentang keluarga berencana mempunyai peluang 11,379 kali lebih besar menyebabkan terjadinya unmet need $\mathrm{KB}$ pada pasangan usia subur.

\section{Umur dengan kejadian unmet need $\mathrm{KB}$}

Hasil penelitian diperoleh $p$-value 0,000 , artinya ada hubungan yang signifikan antara umur dengan kejadian unmet need KB. Hasil analisis diperoleh pula $\mathrm{OR}=27,00$ berarti wanita yang berumur > 35 tahun mempunyai peluang tidak menggunakan alat kontrasepsi (unmet need $K B$ ) sebesar 27 kali lebih tinggi dibandingkan dengan wanita yang berumur $\leq 35$ tahun.

Hasil penelitian ini sejalan dengan penelitian yang telah dilakukan oleh Nanlohy, S (2017) di Kecamatan Panakukang Kota Makasar didapatkan hasil bahwa sebagian besar 
Journal of Healthcare Technology and Medicine Vol. 5 No. 2 Oktober 2019

Universitas Ubudiyah Indonesia

e-ISSN : 2615-109X

responden unmet need termasuk dalam kategori umur reproduksi tua sebanyak 75,5\%, dan ada hubungan umur dengan kejadian unmet need dengan nilai $\mathrm{p}=0.039^{7}$

Berdasarkan hasil penelitian, peneliti menyimpulkan bahwa umur menjadi salah satu determinan yang dapat menyebabkan seseorang tidak menggunakan kontrasepsi (unmet need $K B)$, hal ini dikarenakan wanita yang berumur > 35 tahun berpendapat bahwa apabila umur sudah tua untuk kemungkinan hamil sangat sedikit maka mereka merasa malas untuk kembali kepetugas kesehatan untuk mendapatkan alat kontrasepsi dan merasa tidak nyaman dengan efek samping dari alat kontrasepsi, sehingga mereka memilih tidak menggunakan alat kontrasepsi tersebut.

\section{Pendidikan dengan kejadian unmet need $\mathrm{KB}$}

Hasil penelitian diperoleh $p$-value 0,002 , artinya ada hubungan yang signifikan antara pendidikan dengan kejadian unmet need $\mathrm{KB}$. Hasil analisis diperoleh pula $\mathrm{OR}=17,00$ berarti wanita berpendidikan rendah mempunyai peluang unmet need KB sebesar 17 kali lebih tinggi dibandingkan dengan wanita berpendidikan tinggi.

Hasil penelitian ini sejalan dengan penelitian yang telah dilakukan oleh Usman, Masni dan Arsin tahun 2012 di Kecamatan Kota Tengah Kota Gorontalo Provinsi Gorontalo, didapatkan hasil bahwa besarnya hubungan pendidikan dengan kejadian unmet need $\mathrm{KB}$ (nilai Phi $=-0.016$, hubungan korelasi moderat), dengan arti semakin rendah pendidikan pasangan usia subur maka semakin banyak yang mengalami kejadian unmet need $\mathrm{KB}^{8}$.

Berdasarkan hasil penelitian, peneliti menyimpulkan bahwa pendidikan menjadi salah satu determinan yang dapat menyebabkan seseorang tidak menggunakan kontrasepsi (unmet need $K B$ ), hal ini dikarenakan pendidikan formal yang telah ditempuh menjadikan seseorang memiliki kepribadian dan pengendalian diri yang baik, sehingga akan lebih mudah paham dari berbagai informasi yang didapat termasuk dalam mengunakan alat kontrasepsi.

\section{Pengetahuan dengan kejadian unmet need KB}

Hasil penelitian diperoleh $p$-value 0,018 , artinya ada hubungan antara pengetahuan dengan kejadian unmet need KB. Hasil analisis diperoleh pula $\mathrm{OR}=7,93$ berarti wanita berpengetahuan rendah mempunyai peluang unmet need KB 7 kali lebih tinggi dibandingkan dengan wanita berpengetahuan tinggi.

Hasil penelitian ini sesuai dengan penelitian yang dilakukan oleh Resta (2016), hasil penelitian menunjukkan ada hubungan pengetahuan dengan Unmet Need pada PUS di 
Journal of Healthcare Technology and Medicine Vol. 5 No. 2 Oktober 2019

Universitas Ubudiyah Indonesia

e-ISSN : 2615-109X

Wilayah Kerja Puskesmas Sokaraja II ( $\mathrm{p}=0,007)$. Responden dengan pengetahuan kurang, berpeluang 4,33 kali menjadi unmet need $\mathrm{KB}$ dibandingkan dengan responden yang berpengetahuan baik ${ }^{9}$. Sama halnya dengan penelitian yang pernah dilakukan oleh Ulsafitri dan Fastin di Kelurahan Tarok Dipo Kecamatan Guguk Panjang Kota Bukittinggi dengan hasil terdapat hubungan yang signifikan antara pengetahuan responden terhadap kejadian unmet need $\mathrm{KB}(\mathrm{p}=0,0(\mathrm{p}<0,05) ; \mathrm{OR}=0,079){ }^{10}$.

Berdasarkan hasil penelitian dapat disimpulkan bahwa pengetahuan menjadi salah satu determinan kejadian (unmet need $K B$ ), karenakan pengetahuan ini merupakan hal terpenting bagi seseorang dalam bersikap dan bertindak, salah satunya adalah pengetahuan tentang kontrasepsi dan apa dampaknya apabila apabila pasangan usia subur ingin menjarangkan kehamilan namun tidak menggunakan alat kontrasepsi, sehingga hal ini yang dapat menyebabkan tingginya angka unmet need $\mathrm{KB}$ di Indonesia.

\section{Jumlah Anak dengan kejadian unmet need KB}

Hasil penelitian dapat dilihat bahwa wanita dengan jumlah anak $\leq 2$ dan tidak menggunakan kontrasepsi (unmet need $\mathrm{KB}$ ) sebesar 57,1\%. Hasil uji statistik diperoleh $p$ value 0,002, artinya ada hubungan antara jumlah anak dengan kejadian unmet need $\mathrm{KB}$ di wilayah kerja Puskesmas Peukan Bada Kabupaten Aceh Besar Tahun 2019.

Hasil penelitian ini sejalan dengan penelitian yang dilakukan oleh Ardhika (2018) hasil penelitiannya menunjukkan bahwa jumlah anak memiliki hubungan dengan terjadinya unmet need KB Pasangan Usia Subur (Pus) Di Kecamatan Labuhan Ratu Kota Bandar Lampung dimana P- value=0,006. Bagi PUS yang sudah memiliki anak 2 dapat menjarangkan kelahiran dan menggunakan alat kontrasepsi metode jangka panjang ${ }^{11}$.

Berdasarkan hasil penelitian dapat disimpulkan bahwa jumlah anak menjadi determinan kejadian unmet need $\mathrm{KB}$, hal ini dikarenakan wanita yang baru memiliki anak 2 masih berharap mempunyai anak lagi tetapi tidak dalam waktu dekat, namun rata-rata pasangan usia subur lebih memilih tidak menggunakan alat kontrasepsi karena merasa tidak nyaman dengan efek samping yang dialaminya dan tidak memiliki waktu untuk selalu menjumpai petugas kesehatan untuk ber-KB.

\section{Dukungan Suami dengan kejadian unmet need KB}


Journal of Healthcare Technology and Medicine Vol. 5 No. 2 Oktober 2019

Universitas Ubudiyah Indonesia

e-ISSN : 2615-109X

Hasil penelitian diperoleh $p$-value 0,006, artinya ada hubungan yang signifikan antara dukungan suami dengan kejadian unmet need KB. Hasil analisis diperoleh pula $\mathrm{OR}=12,69$ berarti wanita yang kurang mendapatkan dukungan dari suami mempunyai peluang unmet need KB 12 kali lebih tinggi dibandingkan dengan wanita yang mendapatkan dukungan suami.

Hasil penelitian ini sesuai dengan penelitian yang dilakukan oleh Winengsih (2017), hasil perhitungan uji statistik menggunakan chi-square dapat diperoleh p-value 0,006 < $(0,05)$ sehingga dapat disimpulkan bahwa ada hubungan yang signifikan antara dukungan suami dengan unmet need. Dukungan suami sangat berpengaruh besar dalam pengambilan keputusan menggunakan atau tidak dan metode KB apa yang akan dipakai ${ }^{12}$.

Berdasarkan hasil penelitian dapat disimpulkan bahwa dukungan suami menjadi hal yang sangat penting bagi wanita untuk mengambil sebuah keputusan, salah satunya adalah dalam menggunakan alat kontrasepsi. Kurangnya dukungan dari suami maka dapat meningkatkan unmet need $\mathrm{KB}$, hal ini bisa saja membahayakan kesehatan ibu dan janinnya kelak.

\section{Peran Petugas Kesehatan dengan kejadian unmet need KB}

Hasil penelitian diperoleh $p$-value 0,002, artinya ada hubungan yang signifikan antara peran petugas kesehatan dengan kejadian unmet need KB. Hasil analisis diperoleh pula $\mathrm{OR}=18,00$, berarti kurangnya peran petugas kesehatan dalam memberikan informasi tentang penggunaan alat kontrasepsi memiliki peluang 18 kali lebih besar terjadinya unmet need KB.

Hasil penelitian ini sesuai dengan penelitian yang dilakukan oleh Novianto, Emilia dan Dasuki di Kecamatan Kraton Yogyakarta dengan hasil bahwa Bias provider berhubungan dengan kejadian unmet need KB. Proporsi responden yang mengalami bias informasi dan pelayanan dari provider KB (setelah melibatkan variabel luar) adalah 3,2 kali lebih banyak mengalami bias informasi dan pelayanan dari provider $\mathrm{KB}$, bias petugas lapangan dalam mempengaruhi unmet need KB sebanyak 15\%. Perlu peningkatan kualitas pelayanan untuk memberikan pemahaman tentang alat kontrasepsi ${ }^{13}$.

Konseling Keluarga Berencana taupun Dukungan Petugas Kesehatan merupakan aspek yang sangat penting dalam pelayanan Keluarga Berencana (KB) dan Kesehatan Reproduksi (KR). Dengan melakukan konseling berarti petugas membantu masyarakat dalam memilih dan memutuskan jenis kontrasepsi yang akan digunakan sesuai dengan pilihannya. 
Journal of Healthcare Technology and Medicine Vol. 5 No. 2 Oktober 2019

Universitas Ubudiyah Indonesia

e-ISSN : 2615-109X

Sehingga mereka dapat menentukan kontrasepsi yang aman untuk dirinya agar dapat menghindari efek samping yang terjadi dan berbagai faktor lainnya ${ }^{14}$.

Berdasarkan hasil penelitian dapat disimpulkan bahwa petugas kesehatan memiliki peran yang paling penting dalam merubah perilaku kesehatan seseorang dari hal yang negative menjadi hal positif, salah satunya adalah perilaku pasangan usia subur yang tidak menggunakan alat kontrasepsi (unmet need KB). Pemberi layanan keluarga berencana juga perlu meningkatkan keterampilan komunikasi saat memberikan layanan melalui kegiatan peningkatan kapasitas bagi petugas penyedia dan pemberi layanan keluarga berencana secara berkelanjutan.

\section{KESIMPULAN}

Berdasarkan hasil penelitian dapat disimpulkan bahwa ada hubungan umur ( $p$ value $=0.000, \mathrm{OR}=27,00)$, pendidikan $(p$ value $=0.002, \mathrm{OR}=17,00)$, pengetahuan $(p$ value $=$ $.018, \mathrm{OR}=7,93)$, jumlah anak ( $p$ value $=0.012)$, dukungan suami $(p$ value $=0.006, \mathrm{OR}=12,60)$, peran petugas kesehatan ( $p$ value $=0.002, \mathrm{OR}=18,00)$ dengan kejadian unmet need $\mathrm{KB}$ di Wilayah Kerja Puskesmas Peukan Bada Kabupaten Aceh Besar Tahun 2019. Hasil analisis multivariate didapat variable yang dominan dengan kejadian unmet need adalah peran petugas kesehatan dengan nilai $\mathrm{OR}=11,37$.

\section{SARAN}

Diharapkan kepada para pasangan usia subur yang ingin menunda kehamilan agar sebaiknya memilih salah satu alat kontrasepsi yang sesuai dengan indikasi dan keinginan sendiri, dengan harapan agar terhindar dari unmet need $\mathrm{KB}$ yang dapat merugikan diri sendiri dan anaknya kelak. Dan saran bagi petugas kesehatan agar dapat lebih meningkatkan mutu pelayanan kesehatan. Pemberi layanan keluarga berencana perlu meningkatkan keterampilan komunikasi saat memberikan layanan melalui kegiatan peningkatan kapasitas bagi petugas penyedia dan pemberi layanan keluarga berencana secara berkelanjutan. Bentuk-bentuk program yang dapat dilakukan secara berkesinambungan seperti penyuluhan kesehatan penyuluhan kesehatan, pembimbingan dan pembinaan, pelatihan, pembagian brosur, pemasangan spanduk dan baliho tentang pentingnya menjarangkan kehamilan dengan menggunakan alat kontrasepsi agar dapat menurunkan angka kejadian unmet need $\mathrm{KB}$ dikalangan pasangan usia subur dikarenakan unmet need KB merupakan permasalahan yang 
Journal of Healthcare Technology and Medicine Vol. 5 No. 2 Oktober 2019

Universitas Ubudiyah Indonesia

e-ISSN : 2615-109X

bersifat multidimensional dan bukan hanya akan menjadi penyebab ledakan populasi melainkan juga bisa berpengaruh pada tingginya Angka Kematian Ibu (AKI) di Iindonesia.

\section{UCAPAN TERIMA KASIH}

Ucapan terima kasih kepada Universitas Ubudiyah Indonesia yang telah memberikan dukungan finansial dalam penelitian ini dan ucapan terima kasih kepada Kepala Puskesmas Peukan Bada Aceh Besar yang telah memberikan izin penelitian diwilayah kerjanya dan para responden yang telah membantu peneliti dalam memberikan informasi yang dibutuhkan peneliti.

\section{DAFTAR PUSTAKA}

1. BKKBN. Laporan Kinerja Tahunan Keluarga Berencana. 2017.

2. Kementrian Kesehatan Republik Indonesia. Pedoman Manajemen Pelayanan Keluarga Berencana. Jakarta Salemba Med. 2014:55-58.

3. Bappenas. Rencana Pembangunan Jangka Menengah Nasional (rpjmn) 2015-2019. Kementrian Perenc Pembang Nas. 2015:2015-2019.

doi:10.1017/CBO9781107415324.004

4. Kependudukan I, Pembangunan D, Peran K, Di Balik B, Stunting P. Program KKbPK dalam SdKi 2017. Keluarga. 2018. www.bkkbn.go.id/ISSN:

5. BKKBN. Badan Kependudukan Keluarga Berencana Nasional.; 2017.

6. BKKBN Aceh. Rapat Pengendalian Program (Radalgram)Provinsi Aceh. In: ; 2016.

7. Nanlohy S. Determinan Kejadian Unmet Need Keluarga Berencana di Kecamatan Panakkukang Kota Makassar. Skripsi. 2017:1-85.

8. Usman L, Masni, Arsin AA. FACTOR ASSOCIATED WITH THE INCIDENCE OF UNMET NEED KB ON PUSSY AGAINST UNWANTED PREGNANCES Universitas Hasanuddin , ${ }^{2}$ Bagian Biostatistik Fakultas Kesehatan Masyarakat Universitas Hasanuddin , ${ }^{3}$ Bagian Epidemiologi , Fakultas Kesehatan Masyaraka. 2012.

9. Resta L. Faktor-faktor yang Berhubungan Dengan Unmet Need KB Pada Pasangan Usia Subur di Wilayah Kerja Puskesmas Sokaraja II. J Ilm Kebidanan. 2016;5 (2).

10. Ulsafitri Y, Fastin RN. Faktor-Faktor Yang Berhubungan Dengan Unmet Need Kb Pada Pasangan Usia Subur (Pus). J Ilmu Kesehat 'Afiyah. 2015;2(2). http://ejournal.stikesyarsi.ac.id/index.php/JAV1N1/article/view/54.

11. Ardhika MU. Faktor Penyebab Terjadinya Unmet Need Kb Pasangan Usia Subur (Pus) 
Journal of Healthcare Technology and Medicine Vol. 5 No. 2 Oktober 2019

Universitas Ubudiyah Indonesia

e-ISSN : 2615-109X

Di Kecamatan Labuhan Ratu Kota Bandar Lampung. Fak Kegur dan Ilmu Pendidik Univ Lampung Bandar Lampung. 2018;10 (2).

12. Winengsih E. Faktor-Faktor Yang Mempengaruhi Unmet Need Pada Pasangan Usia Subur Di Kelurahan Kadipaten Kecamatan Kraton Yogyakarta. J Fak Ilmu Kesehat Univ 'Aisyiyah Yogyakarta. 2017;3 (3).

13. Novianto A, Emilia O, Dasuki D. Unmet need KB pada pasangan usia subur di kecamatan Kraton Yogyakarta. Ber Kedokt Masy. 2017:33-36.

14. Azzahra MAFD. Determinan Unmet Need KB pada Wanita Pasangan Usia Subur di Wilayah Kerja Puskesmas Gang Sehat Kota Pontianak. J Cerebellum. 2018;4:971-985. 